\title{
CuVIS: An interactive tool for instructors to create effective customized learning designs with visualizations
}

\author{
Gargi Banerjee, Sahana Murthy \\ Indian Institute of Technology, Bombay
}

Instructors face difficulty in creating student-centred, customized learning designs (LDs) for teaching with information and communication technology (ICT) tools such as visualizations (animations, simulations or videos). This problem is compounded for tertiary-level instructors teaching in instructor-mediated classrooms. In such classrooms, common in many parts of the developing world, students may not have 1:1 access with the visualization and have to interact with it via the instructor. Here, the instructors' pedagogy becomes an important factor determining effective learning with the visualization. To address this problem, a set of design impediments faced by instructors in this context were first identified. Design guidelines were created to address these impediments. These guidelines evolved into the Customized Visualization Integration System (CuVIS). It is a wizard-like interactive tool that provides guidelines to instructors on how to create effective LDs that incorporate the principles of constructive alignment and meaningful learning with ICT, and is customized to instructors' requirements. The effectiveness of CuVIS has been tested with instructors along multiple dimensions: usefulness and usability, impact on instructors' pedagogical practice and impact on student learning when taught with CuVIS-generated LDs.

\section{Introduction}

The use of information and communication technologies (ICT) has the potential to achieve important learning objectives such as increasing learners' conceptual and procedural understanding (Laasko, Myller, \& Korhonen, 2009) and improving reasoning skills (Riess \& Mischo, 2010). The achievement of these objectives is dependent on the way instructors integrate the ICT tools in their teaching. Effective integration is defined as "ICT functioning as an integral or mediated tool to accomplish specific teaching or learning activities to meet certain instructional objectives" (Lim \& Hang, 2003, p. 50). But these objectives remain unrealised when instructors simply lecture with the tool, which has been reported to be one of the most popular strategies used worldwide (Angeli \& Valanides, 2009). This inability of instructors to create student-centred learning designs (LDs) has been identified as an important barrier to effective integration of ICT in teaching (Angeli \& Valanides, 2009; Tsai \& Chai, 2012).

Potential reasons behind this problem are that instructors face difficulty in customizing theories such as teaching principles and frameworks or best practices for their own context (Laurillard, 2012; Schaffer, Akbar, Alon, Stewart, \& Edwards, 2011) and perceiving the pedagogical utility of tool affordances (Webb \& Cox, 2004). However, the identification of specific design impediments faced by instructors in different contexts remains an open question in LD research (Bennett, Agostinho, \& Lockyer, 2015). This problem becomes more challenging when the context is instructors teaching with ICT in instructor-mediated classrooms. In such classrooms, common in many parts of the world, students do not have direct access to ICT, instead interacting with it via the instructor. Thus, the pedagogy of the instructor becomes a crucial factor in effective integration of ICT in such a context.

A common ICT tool used by instructors in the above context is computer-based visualizations, such as animations or simulations. Well-designed visualizations have proven potential in improving learning outcomes for students (Rutten, van Joolingen, \& van der Veen, 2012). However, this potential is lost without effective LDs, due to the above reasons. Existing tools that assist instructors in authoring LDs do not provide guidance to instructors on how to resolve the design impediments that instructors face in technology-constrained contexts, such as lack of 1:1 learner access to the visualizations, nor do they focus on harnessing the affordances of visualizations. This problem is compounded for instructors at the tertiary level, especially in science and 
engineering domains, where content topics become more abstract and instructional objectives are focused on equipping students to transition from the academic to the professional world (Bennett et al., 2015; Coppola \& Krajcik, 2014). Thus, the aim of this research was to develop an LD tool that addresses the identified design impediments for tertiary-level instructors teaching with visualizations and guides them to create effective, student-centred LDs.

In this paper, we present the design, development and evaluation of the tool CuVIS: Customized Visualization Integration System. The target users of CuVIS are science and engineering instructors who teach with visualizations but are novice designers. The classroom context in which they teach is an instructor-mediated one where students do not have individual laptops and cannot directly manipulate the visualization. Student interaction with the visualizations has to be mediated through the instructor. For such instructors, CuVIS is a wizard-like tool that scaffolds them in creating theory-informed, student-centred LDs for teaching with visualizations and is also customized to their context. CuVIS LDs incorporate principles of constructive alignment (Biggs, 1996) and dimensions of meaningful learning with ICT (Howland, Jonassen, \& Marra, 2012). CuVIS was built using design and development research (DDR) methodology, wherein the target users were involved in each step. CuVIS was evaluated from multiple perspectives, such as its impact on instructors' pedagogical practice as well as student learning when taught with CuVIS-generated LDs.

\section{Background}

Multiple solutions have been developed for the problem of instructors' inability to design effective studentcentred LDs. These include instructor training programs and workshops (Lakkala \& Ilomäki, 2015), online portals for sharing best practices (Shaffer et al., 2011), teaching frameworks and guidelines (Biggs, 1996; Howland et al., 2012; Sorva, Karavirta, \& Malmi, 2013) and learning design frameworks (Conole, 2014; Laurillard, 2013) and tools (Laurillard, 2012; Lukasiak et al., 2005). Analysis of existing solutions reveal that while training programs are effective in assisting instructors in translating theory into practice, the majority of them are at K-12 level. What exists for tertiary-level instructors are typically short in-service workshops. Moreover, such workshops are reported to be insufficient to develop instructors' ability to design effective LDs (Conole \& Alevizou, 2010). The existing array of teaching frameworks and guidelines provide the requisite know-how on what constitutes effective teaching. However, they do not provide guidance to instructors who are novice designers on how to apply these theories in their own context.

LDs have been developed to bridge this gap between theory and practice (Laurillard, 2012). The existing LD frameworks and tools guide instructors in authoring student-centred LDs with ICT tools. However, comparative analysis of LD frameworks and tools reveals that most provide guidelines at a broad level. For example, both the Learning Designer tool (Laurillard, 2012) and the 7C framework (Conole, 2014) inform instructors of the importance of constructive alignment. To assist in operationalizing constructive alignment, the Learning Designer provides a set of reviewed LDs created by other instructors for the same type of approach, such as collaborative learning, inquiry-based learning. Instructors can refer to these existing LDs while designing. But they are known to face difficulty in customizing existing best practices for their context (Shaffer et al., 2011). On the other hand, the 7C framework informs the instructor at what stage of the LD creation process they should consider operationalizing constructive alignment. In this context, the problem faced by instructors is that existing LD tools and frameworks do not provide customized guidance on how to operationalize constructive alignment in an LD.

Instructors also face difficulty in recognizing the pedagogical utility of tool affordances (Web \& Cox, 2004). However, LD tools such as Learning Designer (Laurillard, 2012) and CADMOS (Katsamani \& Retalis, 2011) do not focus on how to exploit the affordances of a specific ICT tool. Hence, such guidelines need to be incorporated in LD authoring tools for instructors. Another problem encountered is the objective of the majority of tools such as CADMOS and Webcollage (Villasclaras-Fernandez et al., 2011) is to reach out to a broader audience in an online setting. But contextualizing them to settings such as instructor-mediated classrooms is needed because these settings are prevalent in many parts of the developing world. Also, in these settings the instructor's pedagogy becomes a crucial factor in achieving effective teaching-learning with ICT. 
These gaps in existing solutions led us to our research objective, that is, to develop an LD tool that would fulfil the following requirements:

- provide guidelines to instructors on how to translate theory into practice in their context

- guide in exploiting visualization affordances to create an effective LD

- be easily comprehensible and usable to tertiary-level instructors (who typically do not have formal background in education theory)

- incorporate the challenges of an instructor-mediated setting.

\section{The CuVIS tool}

\section{Overview of the tool}

CuVIS is a semi-automatic, wizard-like LD authoring tool for instructors. It scaffolds them in creating a theoryinformed, research evidence-based LD for their chosen topic, learning objectives and visualization. The CuVISgenerated LD maps to the instructor's learning objectives, includes collaborative student-centred activities based on the visualization and activities which promote self-reflection among students, real-life application of the topic being taught, and is customized to the context of the instructor-mediated setting.

To generate such an LD, instructors interact with the CuVIS tool in two stages (Figure 1). They first specify customisation parameters such as their domain, learning objectives and preferred activity time duration. In the next stage, they respond to a set of activity constructor prompts. The prompt set is mapped to the customisation parameters specified. Each prompt contains guidelines with illustrative domain examples that guide instructors to take design decisions at appropriate points in the LD creation process. Once the design decisions have been provided, CuVIS automatically retrieves the LD blueprint from the back end, which maps to the instructor's objectives and activity time duration preference. The blueprint is a fill-in-the-blank template which outlines the theory-recommended classroom implementation design in steps and ensures the final LD is constructively aligned. The blueprint is automatically filled in by CuVIS with the instructor's responses to the prompts. The output is thus an effective customized LD for teaching with visualizations (Figure 1).

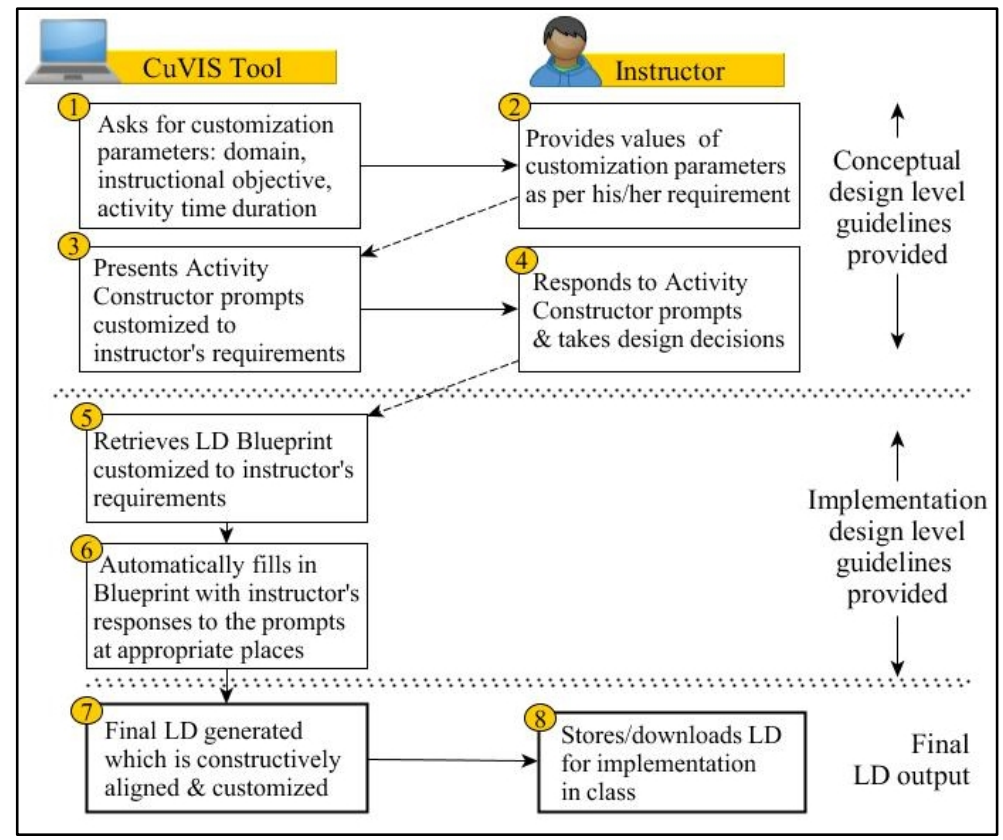

Figure 1. Overview of functioning of CuVIS tool 
The tool is useful for instructors who teach using visualizations but are novice designers. CuVIS scaffolds them through guidelines and illustrative examples to overcome the four design impediments identified from our studies with instructors:

- mapping the teaching-learning activity to the instructor's objective

- incorporating the five known dimensions of meaningful learning in the LD

- framing group activity questions (conceptual level)

- designing student-centred classroom implementation design (implementation level).

The final output they receive is an effective LD customized to a learning scenario of their choice.

\section{Theoretical underpinnings of CuVIS}

The theoretical underpinnings of CuVIS are the teaching principles of constructive alignment (Biggs, 1996) and meaningful learning with ICT (Howland et al., 2012). Constructive alignment specifies what constitutes effective teaching; that is, to successfully attain the learning objective of a teaching unit, both the teachinglearning activity and the assessment designed should map to the learning objective within a constructivist pedagogy. Empirical studies have shown the positive impact of this principle on student learning in multiple science domains (Morris, 2008). This principle forms the basis of the CuVIS guidelines both at conceptual and implementation levels. Meaningful learning with ICT, on the other hand, outlines which dimensions need to be present in the LD to ensure meaningful learning. It identifies five such dimensions (Howland et al., 2012):

- Active learning - students actively engage with ICT content.

- Constructive - students use ICTs to construct their own knowledge through self-reflection and articulation.

- Authentic - students devise solutions to real-life problems using ICTs.

- Intentional - students set their learning goals, evaluate their understanding and self-diagnose their errors through ICTs.

- $\quad$ Cooperative - students do group activity with their peers using ICTs.

This principle informs the framing of CuVIS guidelines at the conceptual level.

\section{Functioning of the CuVIS tool}

The design of the CuVIS tool is informed by the learning by design model for instructors (Kali \& RonenFuhrmann, 2011), which consists of three elements - the ADDIE structure, the design principles database that provides required expert knowledge to assist in designing and the studio instructional approach. In CuVIS, the user is taken through steps of the LD creation process based on the ADDIE structure. After an initial user specification step, CuVIS proceeds through the analysis, design and development stages of ADDIE (Figure 2). In each step, the user is guided to take design decisions on the in-class activity and is asked to respond to a set of guidelines mapped to the chosen objective and activity time duration. These guidelines map to the design principles database of the learning by design model. Once the design decisions are taken, CuVIS retrieves the relevant LD blueprint and automatically plugs in the design decisions taken by the user in the appropriate places to complete the creation of the LD. To include the third element of the studio approach, $\mathrm{CuVIS}$ provides opportunities for instructors to pursue open-ended activities such as LD creation for their chosen learning scenario. However, peer and mentor feedback can be received external to CuVIS. Thus, the final output from CuVIS is an LD that contains the user's design decisions, which makes the LD constructively aligned and in support of all the dimensions of meaningful learning with ICT. 


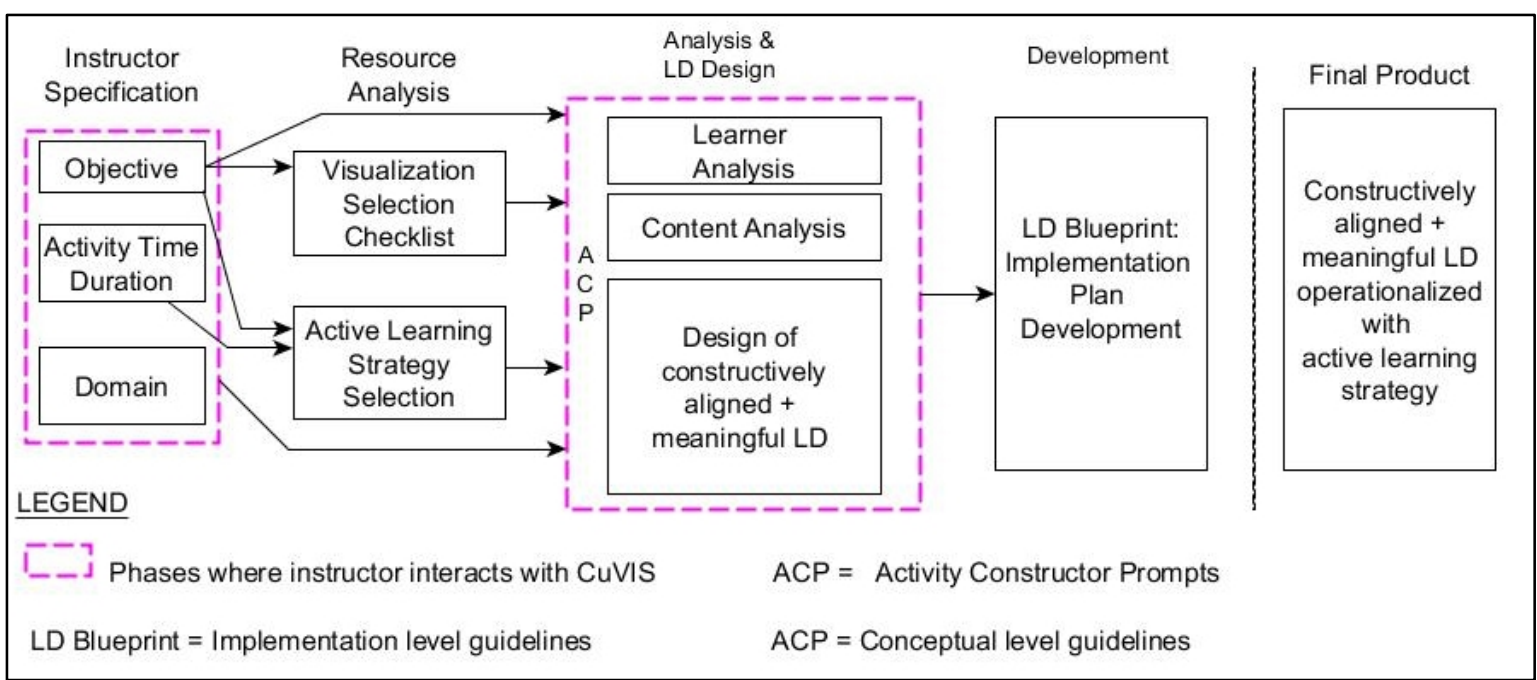

Figure 2. Block diagram of working of CuVIS tool

Once users log in, they are taken through the following steps (Figure 2):

(1) Instructor specification step - Instructors input their specific requirements by choosing from a given list of learning objectives, domain (Computer Science and Engineering (CS), Electrical Engineering (EE), activity time duration (short $=5-10$ minutes; long $=15-20$ minutes) and setting (Lecture, Tutorial) (Figure 3). These lists of customization specifications emerged from the analysis of interviews with our target user population.

(2) Analysis step - This has two sub-steps: resource analysis and learner and content analysis. In resource analysis, CuVIS provides a visualization selection checklist that contains a list of affordances the visualization should have to support effective teaching of the chosen objective. CuVIS also suggests an active learning strategy mapped to a specific combination of objective and activity time duration (Figure 4). These strategies (e.g., peer instruction) are such that they support all the dimensions of meaningful learning with ICT. As part of learner analysis, CuVIS provides guidelines through prompts that spur instructors to think about student difficulty in understanding the topic. Content analysis takes place in tandem. Here, users analyze the chosen content to think of ways to operationalize the theories of constructive alignment (Figures 5 and 6) and meaningful learning with ICT (Figure 6) for their chosen topic. 


\section{CuVIS: Customized Visualization Integration System}

Welcome to the CuVIS tool. This tool will help you to generate a theory-informed, research-based Lesson Plan for your topic. This lesson plan will be mapped to your objective and customized to your requirements. You will proceed through a set of 'Activity Construction' prompts to generate the lesson plan.

Step 1: Enter your data below to specify the topic and instructional context.

Step 2: Select your learning objective from the given set.

Step 3: Cross-check if your selected visualization has all the features recommended by CuVIS

Step 4: Respond to a set of 'Activity Construction' prompts. (ACP)

Step 5: Your Lesson Plan for the chosen topic is ready for saving/download.

Tool Workflow

Domain:

Please select your domain

\section{Course Name}

type your course name here

Topic Name

type your topic name here

Instructional Setting

- Lecture Tutorial

Instructional Objectives with visualization

Visualize to explain a concept with illustration.

Visualize to explain the working of a process/ algorithm OR,Compare multiple processes.

Use a given visualization to compute the solution to the given problem involving multiple prov

Predict output of next step or a set of steps in a multi-step process.

Predict output of a phenomenon.

Students devise an explanation for a given process or phenomena, through logical reasoning, from observations made from the visualization, before they have been taught the topic

Note: Select the instructional objective that best matches with your objective. To view example of each objective roll mouse ove text

Figure 3. Sample screenshot of instructor specification step in CuVIS

In this section, you will be taken through a set of interactive steps to create your 'Lesson Plan'. A 'Lesson Plan' gives you the full implementation plan in steps. For each step, it guides you to plan out the time for each step, what instructor will do, what student will do, what visualization features to use, if any.

Note:

- The 'Lesson Plan' follows a pedagogical pattern of play-pause-do an activity - resume visualization

- Your responses to a set of 'Activity Construction' prompts will be stored. You can change your response whenever you want to.

- Based on your responses to these prompts, CuVIS will generate a 'Lesson Plan' tailored to your requirements. You can download and edit the 'Lesson Plan' as you wish

Choose your preferred activity duration : 5-10 Minutes 15 -20 Minutes

Strategy Suggested for your Objective: Peer Instruction

Strategy

1. Click on this link to know more about Peer Instruction https $/ /$ resinetworkshopSelection iitb. wistia.com/medias/pia8psnf6q

2. Click on 'Next' to proceed through a set of 7 Activity Construction Prompts to create your learning design

Figure 4. Sample screenshot of strategy selection step in CuVIS 


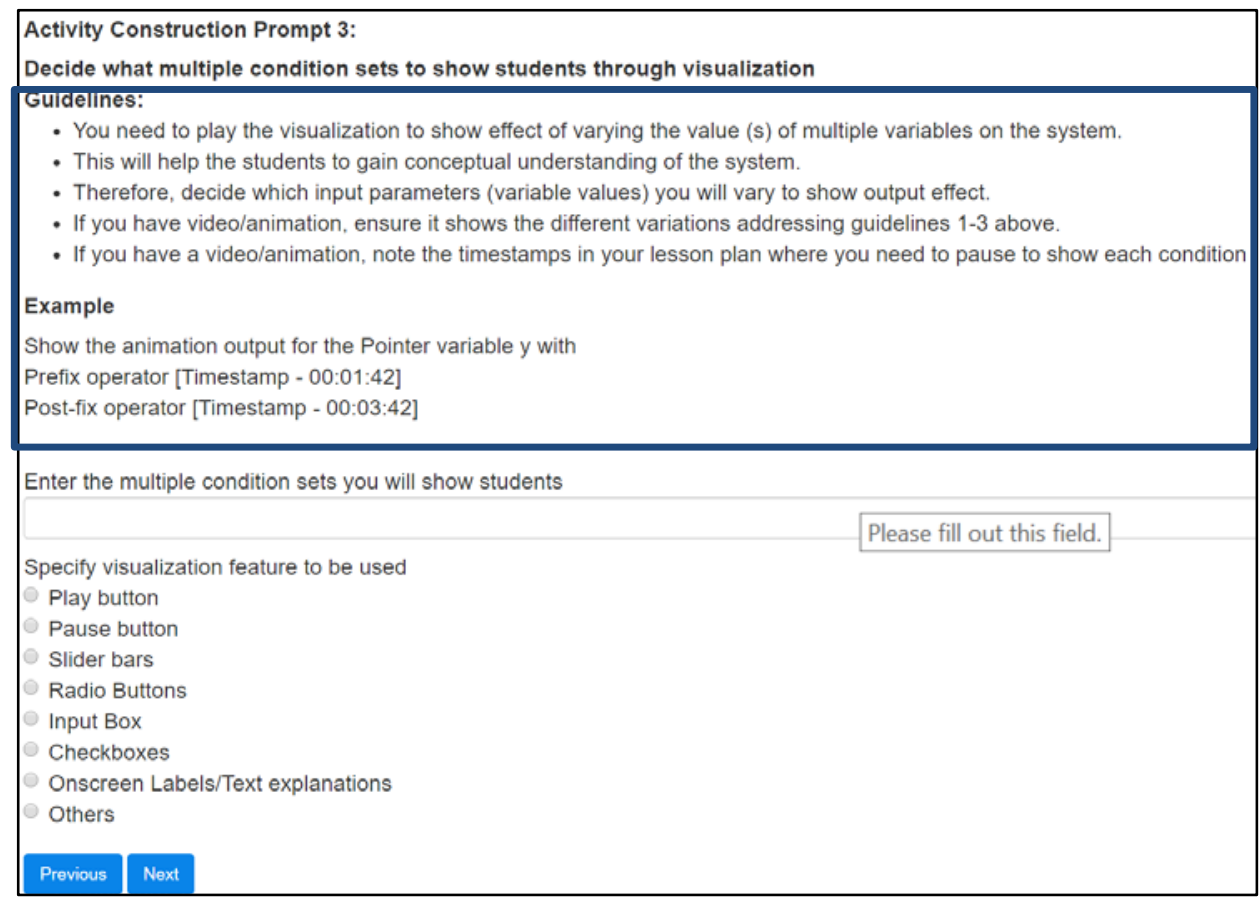

Figure 5. Sample screenshot of constructive alignment guideline

(3) Design step - In this step, users take a series of conceptual level design decisions through a set of activity constructor prompts. These prompts guide users to take decisions that address the three conceptual level design impediments. Each activity constructor prompt has 3 or 4 sections (Figure 6), such as the design decision the instructor has to make, the conceptual level design guideline to operationalize that decision, illustrative example of the design decision in a domain, and the user input area, that is, an input box where users enter their design decision and the radio buttons to specify which visualization affordance will be used to execute that design decision. CuVIS retrieves the appropriate prompt from the relevant mapping tables at the back end. The content in the set of prompts varies with the learning objective, activity time duration and domain specifications.

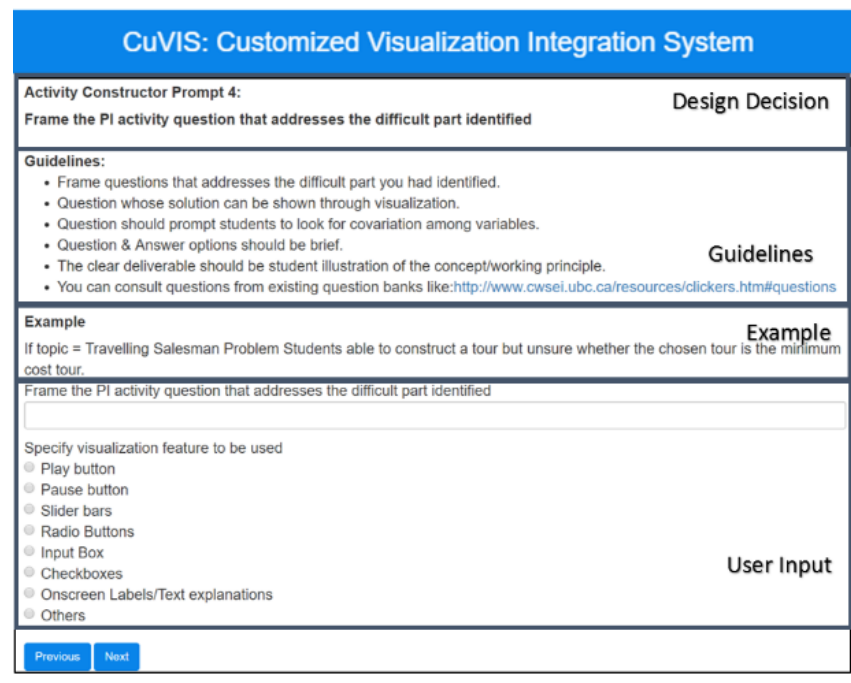

Figure 6. Sample screenshot of activity constructor prompt (framing group activity questions guideline) 
(4) Development step - In this step, CuVIS automatically plugs the design decisions the user has taken at appropriate places within a relevant LD blueprint template. It thus generates an effective studentcentred LD (Figure 7), customised to the instructor's requirement, as output. CuVIS contains a set of such templates mapped to the selected objective and instructional strategy at the back end. Each step in the blueprint outlines the action to be taken by the instructor, expected student response, recommendations for time spent, and the visualization feature to be used. The activity constructor prompts and LD blueprints are customized to instructor requirements such as setting and activity time duration.

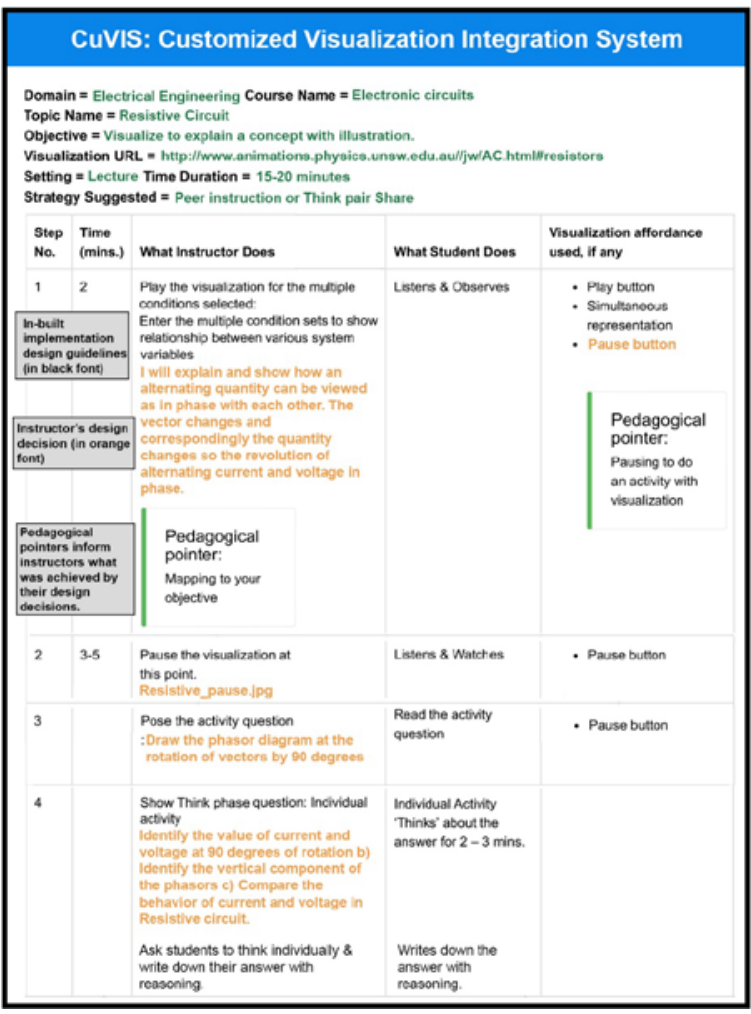

Figure 7. Screenshot of section of a CuVIS-generated LD created by an instructor

\section{Research methodology}

To develop a solution that would be practically viable for instructors, we needed to identify specific design impediments that instructors in our context faced and develop guidelines to address these impediments. These guidelines should be framed in such a way that they are usable and useful to our instructors. Finally, we also needed to establish that the solution developed is effective in resolving the problem of instructors being unable to create student-centred LDs. Therefore, the chosen methodology should enable us to create a systematic solution for this real-life problem which would work in our research context. This can be achieved only if our target user population, that is, tertiary-level instructors teaching with visualizations in instructor-mediated settings, are involved in each step of the solution building.

These requirements of our research methodology are fulfilled by DDR methodology, which focuses on developing tools or models (Richey \& Klein, 2014). We chose DDR as our research methodology since we aimed to develop a practically viable tool as a potential solution to the identified educational problem. For this, the tool development had to progress through iterative feedback cycles involving the instructors. The DDR methodology proceeds through three phases: problem analysis, design and development and evaluation (McKenney, 2001, p. 19) (Figure 8). 


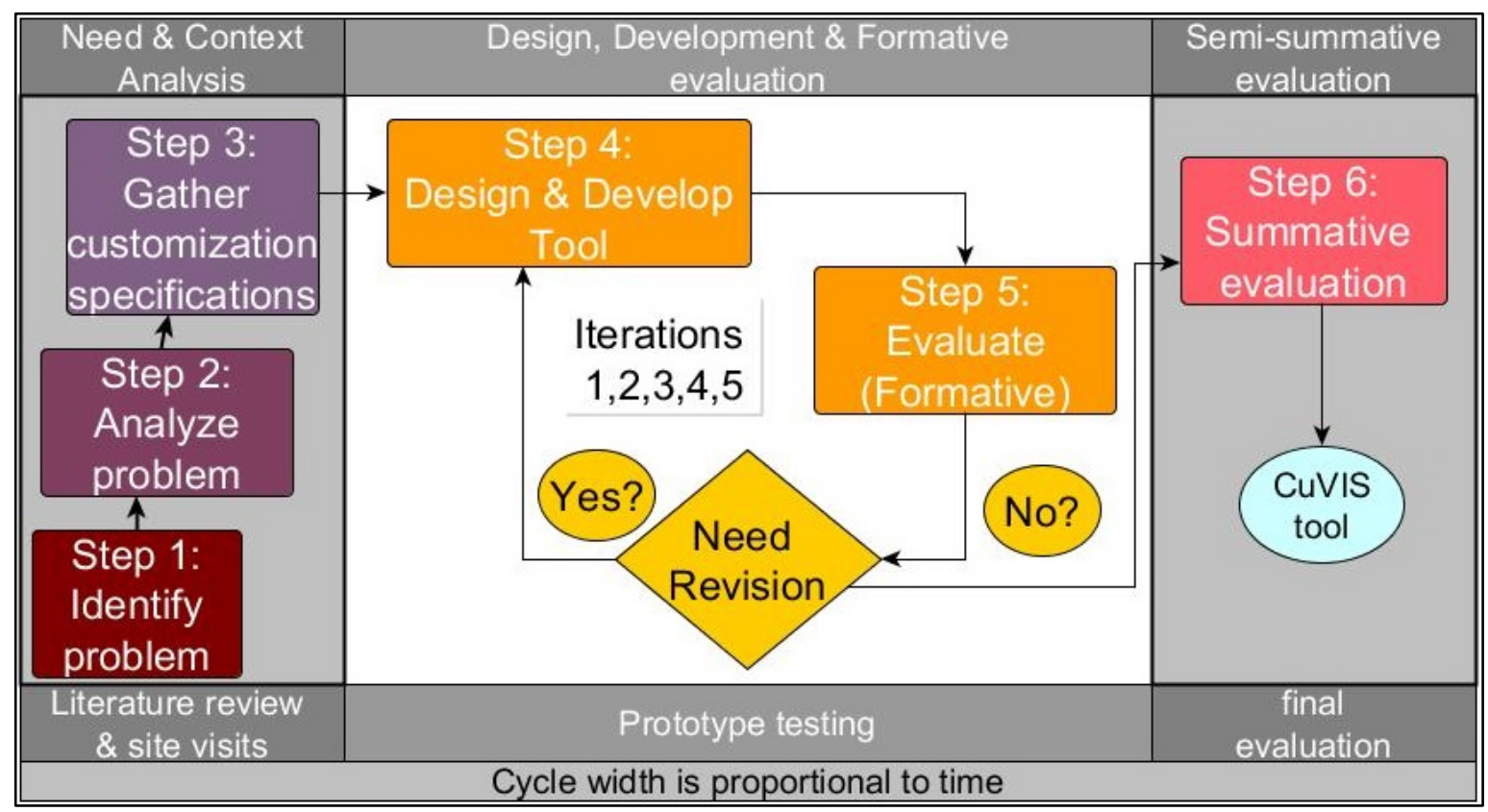

Figure 8. Using DDR to build the CuVIS tool (diagram adapted from McKenney, 2001)

\section{Application of DDR}

Here, we present an overview of how DDR was applied to create the CuVIS tool (Figure 8). In Step 1, the broad problem of instructors not being able to create student-centred LDs was identified from the literature analysis. In Step 2, we analyzed the problem in our research context and identified the specific design impediments that CuVIS needed to address. In Step 3, we interviewed instructors to obtain the customization specifications for LDs that instructors require while teaching using visualizations. In Step 4, we designed and developed guidelines that addressed the identified design impediments, along with accommodating the customization specifications. These guidelines emerged from the analysis and synthesis of multiple streams of literature on cognitive process, pedagogy, visualization affordances and active learning. Step 4 progressed in iteration with Step 5. In Step 5, the guidelines developed were tested for usefulness and usability with instructors. The guidelines were revised based on the feedback received through focus interviews with instructors, after their experience of using CuVIS. The revised guidelines were again tested with instructors until the instructors were satisfied. In Step 6, we carried out effectiveness testing of the CuVIS tool along three dimensions: usefulness and usability of tool, impact of CuVIS on the pedagogical practice of instructors and impact on student learning when taught with CuVIS-generated LDs.

Steps 2-6 each involved instructors from our target population, and a part of Step 6 involved students. The following ethical considerations were followed for all the studies since they involved human participants: Information about the purpose and implication of each study was given to the participants by the researchers, informed consent was obtained via forms signed by participants (both instructors and students), and participants were assured of anonymity and confidentiality.

\section{Participants}

Participants in all studies were science and engineering instructors, across India, who had attended a pedagogy training workshop and were thus aware of the benefits of active learning. They had taught with visualizations in an instructor-mediated classroom setting, but were novices in applying research-based principles to design student-centred teaching-learning activities. They were drawn from the set of 2410 instructors who underwent 
our online training program on effective teaching practices for ICT integration under the Indian Government's National Mission of Education through ICT.

\section{Building the CuVIS tool}

\section{Problem analysis step}

Literature analysis gave us a set of broad possible reasons behind the problem; for example, instructors find it difficult to translate theory into practice (Laurillard, 2012) or customize best practices for their own context (Schaffer et al., 2011). However, for our solution to be relevant to our target users, we needed to analyze the problem in our research context and identify where in the LD creation process instructors needed support. These instructors were selected based on the quality of their workshop submissions (average to good). A qualitative study was done with the 30 instructors who consented to participate. They created LDs for teaching using visualizations for learning scenarios of their choice. We analyzed these LDs using inductive content analysis. We found design impediments at a more granular level than those reported in the literature, and classified them into conceptual level and implementation level impediments. Conceptual level impediments involved difficulty in translating theory into practice, whereas implementation level impediment referred to difficulty in planning implementation as per the protocol of the chosen strategy. Thus, from this study we identified four design impediments that needed to be addressed (Table 1).

Table 1

Identified design impediments where instructors need support to create effective LDs

\begin{tabular}{lll}
\hline Design impediment & Instructor inability & Observed difficulty \\
\hline Conceptual level & $\begin{array}{l}\text { Operationalizing } \\
\text { constructive alignment }\end{array}$ & $\begin{array}{l}\text { Activity question not mapped to objective } \\
\text { Teaching-learning activity not mapped to } \\
\text { objective }\end{array}$ \\
& $\begin{array}{l}\text { Operationalizing dimensions } \\
\text { of meaningful learning } \\
\text { LDs not student-centred, constructive, } \\
\text { cooperative; does not include real-life application } \\
\text { nor promotes student reflection involving } \\
\text { visualization }\end{array}$ \\
& $\begin{array}{l}\text { Framing group activity } \\
\text { questions based on } \\
\text { visualization }\end{array}$ & $\begin{array}{l}\text { group activity } \\
\text { Not exploiting visualization affordances to design } \\
\text { group activity }\end{array}$ \\
& $\begin{array}{l}\text { Fesigning implementation } \\
\text { Implementation level }\end{array}$ & What students should do not adequately specified \\
\hline
\end{tabular}

\section{Gathering customization specifications}

In Step 3, our objective was to identify the type and range of customization parameters CuVIS needed to accommodate, to be useful to our instructors. The instructors in this study were drawn from our target population but had not attended our workshop. We contacted the top five engineering colleges in our region by email, and the study was conducted via face-to-face semi-structured interviews with the instructors who consented. Participants were 28 instructors from multiple domains of Science and Engineering with teaching experience of 5-20 years. The sample size was determined by data saturation. Each instructor was interviewed for 45 minutes on an average. Sample questions asked during the interview were:

- Show examples of visualizations you have used in your teaching.

- What was the learning objective while teaching with each of those visualizations?

- How did you teach with this visualization?

- What was the instructional setting like (classrooms or laboratory) and what factors of your context influenced your learning design? 
We conducted a thematic analysis of these interviews and found nine objective types that instructors generally had while teaching with visualizations. Only seven deep level objectives were included in CuVIS, which mapped to the following Bloom's taxonomy levels (Anderson et al., 2001) - understand, apply and analyse. However, many of these objectives were at the same Bloom level but targeted a distinctly different skill, such as prediction or multiple representation. Hence, they had to be treated differently for effective constructive alignment. Table 2 shows the objectives considered in CuVIS, illustrative examples from the Electrical Engineering domain and the skill targeted.

Table 2

Deep learning objectives for teaching with visualizations addressed by CuVIS tool

\begin{tabular}{|c|c|c|c|}
\hline Learning objectives & Student learning outcomes & $\begin{array}{l}\text { Bloom's } \\
\text { level }\end{array}$ & Skill targeted \\
\hline $\begin{array}{l}\text { Visualize to explain a concept } \\
\text { with illustration. }\end{array}$ & $\begin{array}{l}\text { Explain how electric vector, } \\
\text { magnetic vector propagate as an } \\
\text { electromagnetic wave. }\end{array}$ & Understand & $\begin{array}{l}\text { Conceptual } \\
\text { understanding }\end{array}$ \\
\hline $\begin{array}{l}\text { Visualize to explain the } \\
\text { working of a process/algorithm } \\
\text { or compare multiple processes. }\end{array}$ & $\begin{array}{l}\text { Explain how system response can be } \\
\text { calculated by graphically } \\
\text { convolving system excitation signal } \\
\text { and impulse response of the system. }\end{array}$ & & $\begin{array}{l}\text { Procedural } \\
\text { understanding }\end{array}$ \\
\hline $\begin{array}{l}\text { Write/draw alternate } \\
\text { representations (like graph to } \\
\text { equation) from the given } \\
\text { visualization or vice-versa. }\end{array}$ & $\begin{array}{l}\text { Given mathematical function, draw } \\
\text { the vector field \& vice versa. }\end{array}$ & Apply & $\begin{array}{l}\text { Multiple } \\
\text { representation }\end{array}$ \\
\hline $\begin{array}{l}\text { Use a given visualization to } \\
\text { compute the solution to the } \\
\text { given problem involving } \\
\text { multiple processes. }\end{array}$ & $\begin{array}{l}\text { Given the input signal \& output } \\
\text { signal equations, write the } \\
\text { transformation equations of the } \\
\text { intermediate steps. }\end{array}$ & & $\begin{array}{l}\text { Multi-process } \\
\text { problem-solving }\end{array}$ \\
\hline $\begin{array}{l}\text { Predict output of a } \\
\text { phenomenon. }\end{array}$ & $\begin{array}{l}\text { Predict frequency components of a } \\
\text { signal while sampling when the } \\
\text { signal is under-sampled. }\end{array}$ & & Prediction \\
\hline $\begin{array}{l}\text { Predict output of next step or a } \\
\text { set of steps in a multi-step } \\
\text { process. }\end{array}$ & $\begin{array}{l}\text { Predict the direction of rotation of } \\
\text { the field in electromagnetic wave } \\
\text { polarization }\end{array}$ & & Prediction \\
\hline $\begin{array}{l}\text { Devise an explanation for a } \\
\text { given process or phenomena, } \\
\text { through logical reasoning, from } \\
\text { observations made from the } \\
\text { visualization, before the topic } \\
\text { has been taught. }\end{array}$ & $\begin{array}{l}\text { Derive the plot of ID vs. VGS for } \\
\text { junction field effect transistors } \\
\text { (JFET) from observations made } \\
\text { from the visualization }\end{array}$ & Analyze & $\begin{array}{l}\text { Inquiry-based } \\
\text { learning }\end{array}$ \\
\hline
\end{tabular}

Additional customization parameters identified were activity time duration, instructional setting and type of visualization used.

\section{Design, development and formative evaluation}

The objective of Step 4 was to design and develop the guidelines to resolve the design impediments (Table 1). This step progressed in iteration with Step 5, wherein the usability and usefulness of the guidelines were tested with instructors. In this sub-section, we present the design and development of the guidelines developed for conceptual level impediments (conceptual level guidelines) first, followed by the same for guidelines developed for implementation level impediments (implementation level guidelines) and then the formative evaluation of both. 
Design and development of conceptual level guidelines

Conceptual level guidelines were created to guide instructors in translating theory into practice in their own context for the design impediments identified (Table 1), that is, how to design LDs to achieve constructive alignment, frame group activity questions based on the visualization, and incorporate five dimensions of meaningful learning with ICT. These guidelines were framed through analysis and synthesis of literature on the following:

- the cognitive process that students need to follow to achieve a particular learning objective

- what type of pedagogical support instructors can provide to facilitate that process

- what type of visualization affordances can be used to aid the cognitive process

- active learning strategy protocols that are known to successfully achieve that particular objective using visualization.

From the many that exist, we shortlisted three active learning strategies - peer instruction, think-pair-share and predict-observe-explain - as example strategies in CuVIS. Our aim was to enable instructors who are novice designers experience designing for active learning in depth. They are then likely to become adept at adapting any active learning strategy for their context. This literature synthesis led to guidelines on how to achieve constructive alignment, that is, how to create instructional activities with visualizations mapped to objectives, as well as guidelines for framing group activity questions (formative assessment) such that the questions are mapped to the objective and the selected strategy (Figure 6). We also looked at the literature on evaluation instruments for meaningful learning with ICT to frame guidelines addressing this impediment for forming group activity questions.

Design and development of implementation level guidelines

Guidelines for the implementation design impediment were framed based on the protocol of the shortlisted strategies and the conceptual level guidelines. Thus, the LD blueprint contained a sequence of implementation steps mapped to the protocol of the chosen strategy (Figure 7). Each such step was also aligned to the cognitive process for that objective, as well as the meaningful learning dimensions. These guidelines are thus mapped to the chosen objective and activity time duration specification. The blueprints potentially guide against violation of implementation fidelity, which is a commonly reported problem (Froyd, Borrego, Cutler, Henderson, \& Prince, 2013).

Formative evaluation of conceptual and implementation level guidelines

The usefulness and usability of the conceptual level guidelines was ensured through two rounds of iterative testing with instructors (Table 3). In iterations 1 and 2, the usefulness and usability of the conceptual level guidelines was tested with instructors from Electrical Engineering, and Computer Science and Engineering. The details of the sample and the method followed for testing are given in Table 3. Feedback received from instructors at the end of each iteration was incorporated to generate a revised version of the guideline, which was again tested. The usefulness and usability of the implementation level guidelines, that is, LD blueprints, were evaluated through three iterations (Table 3). Details of each iteration are given in Table 3. Feedback received at each iteration pertained to the usability of the blueprint, with instructors requiring more detailed guidelines to design the implementation plan. 
Table 3

Summary of all 5 iterative cycles for formative evaluation of CuVIS guidelines

\begin{tabular}{|c|c|c|c|c|}
\hline Iteration & Item tested & Focus & Testing method & Feedback \\
\hline 1 & $\begin{array}{l}\text { Conceptual level } \\
\text { guidelines v. } 1\end{array}$ & $\begin{array}{l}\text { Usefulness \& } \\
\text { usability of } \\
\text { conceptual } \\
\text { level guidelines }\end{array}$ & $\begin{array}{l}\text { - } 6 \text { instructors from EE \& CS } \\
\text { - Used CuVIS guidelines to } \\
\text { take design decisions for } \\
\text { creating their LD } \\
\text { - Then a face-to-face focus } \\
\text { interview conducted about } \\
\text { their experience }\end{array}$ & $\begin{array}{l}\text { More explanation } \\
\text { needed for guidelines } \\
\text { on framing group } \\
\text { activity question so } \\
\text { that it conforms to } \\
\text { good features of the } \\
\text { selected strategy }\end{array}$ \\
\hline 2 & $\begin{array}{l}\text { Conceptual level } \\
\text { guidelines v. 2: } \\
\text { Added list of good } \\
\text { features of the } \\
\text { activity question }\end{array}$ & & $\begin{array}{l}\text { - } 10 \text { instructors from EE \& } \\
\text { CS, different from above set } \\
\text { - Same method as above }\end{array}$ & $\begin{array}{l}\text { Guidelines on framing } \\
\text { activity questions } \\
\text { were usable }\end{array}$ \\
\hline 3 & LD blueprint v. 1 & $\begin{array}{l}\text { Usefulness \& } \\
\text { usability of } \\
\text { implementation } \\
\text { level guideline }\end{array}$ & $\begin{array}{l}\text { - } 12 \text { instructors from EE \& } \\
\text { CS used LD blueprint v. } 1 \text { to } \\
\text { generate LDs } \\
\text { - These LDs were studied by } \\
\text { researcher for incorrect } \\
\text { operationalization of } \\
\text { guidelines } \\
\text { - Then face-to-face semi- } \\
\text { structured interviews } \\
\text { conducted with subset of } 8\end{array}$ & $\begin{array}{l}\text { Add more } \\
\text { specifications like } \\
\text { time budgeting for } \\
\text { each step (max. } 5 \\
\text { mins) + prompt } \\
\text { instructor to specify } \\
\text { which visualization } \\
\text { affordance is to be } \\
\text { used at that step }\end{array}$ \\
\hline 4 & $\begin{array}{l}\text { LD blueprint v. 2: } \\
\text { Added prompts at } \\
\text { each step for } \\
\text { instructor to } \\
\text { specify time budget } \\
\text { (max. } 5 \text { mins) \& } \\
\text { affordance to be } \\
\text { used, if any }\end{array}$ & & Same as above & $\begin{array}{l}\text { Give a wizard-like } \\
\text { tool that asks the } \\
\text { instructor a set of } \\
\text { questions, take their } \\
\text { response and generate } \\
\text { the desired LD }\end{array}$ \\
\hline 5 & $\begin{array}{l}\text { LD blueprint v. 3: } \\
\text { Developed fill-in- } \\
\text { the blank templates } \\
\text { where CuVIS will } \\
\text { automatically plug } \\
\text { in instructor’s } \\
\text { design decisions at } \\
\text { appropriate points }\end{array}$ & & $\begin{array}{l}\text { For } 10 \text { instructors from EE } \\
\text { same as above }\end{array}$ & Found satisfactory \\
\hline
\end{tabular}

Notes. EE = Electrical Engineering; CS = Computer Science and Engineering.

\section{CuVIS: summative evaluation}

We measured the effectiveness of CuVIS (Step 6) along the following dimensions:

(1) usefulness and usability of the tool with instructors from multiple domains through a large-scale survey $(N=1200+)$

(2) impact of CuVIS on instructors' pedagogical practice through a semester-long qualitative study, via analysis of instructor-created LDs at multiple time points $(N=6)$

(3) impact of CuVIS-generated LDs on student learning through multiple control-group field experiments with students $(N=375)$. 
Participants in all studies above were Science and Engineering instructors who had attended a prior training workshop (details provided earlier in Research methodology section).

\section{Usefulness and usability}

The research question addressed was: What is the instructor perception of usefulness and usability of CuVIS tool? (RQ1).

\section{Participant characteristics}

The instructors hailed from nine domains: Electrical Engineering $(N=202)$, Civil Engineering $(N=30)$, Computer Engineering $(N=778)$, Mechanical Engineering $(N=121)$, Biotechnology $(N=15)$, Physics $(N=$ 23), Chemistry $(N=18)$, Earth Science $(N=9)$ and Mathematics $(N=20)$. Their teaching experience was in the range of $0-30$ years. A total of 1219 instructors responded to the usefulness survey and 1290 to the usability survey.

\section{Instruments}

We used two evaluation instruments: technology acceptance model (TAM) (Davis, 1989) and system usability survey (SUS) (Brooke, 1996). TAM was used to measure usefulness in terms of whether CuVIS enhanced instructors' teaching effectiveness with visualizations and made the process of LD creation more efficient. It contained 10 items on a 5-point Likert scale, where $1=$ strongly disagree and $5=$ strongly agree (Table 4 ). The reason for choosing TAM is that it has been widely used to predict user adoption and use of new technological tools including educational tools (Curlango-Rosas, Ponce, Lopez-Morteo, \& Mendiola, 2009). We used the 10item SUS evaluation (Brooke, 1996) to capture instructor perception of usability. SUS is widely used for assessing the usability of a wide variety of products and services. We asked an additional question in each TAM and SUS (Q11, Table 4) to capture instructor overall perception on gross usefulness and usability of the CuVIS tool.

\section{Procedure}

Instructors used the CuVIS tool to generate LDs with their selected visualization for their chosen topic and objective. They then responded to the usefulness and usability surveys. To safeguard against conclusion validity threat, we conducted data validation in terms of non-blank LD submissions by respondents. We then sampled all the responses from all the domain units.

\section{Results}

Analysis of the usefulness survey data revealed that $89.13 \%$ of 1219 instructors who responded to the survey perceived CuVIS tool to be a useful resource for creating LDs with visualizations (Table 4). The SUS survey responses were used to calculate the SUS score as per the standard method (Brooke, 1996). The SUS score came to 78.86, indicating the product is usable. Also, 92.18\% of respondents (to Q11 in the usability survey) perceived the usability of the CuVIS tool as good to excellent. Table 4 shows the response analysis for each question in the usefulness survey where the percentage of agree represents the sum of number of respondents who gave either strongly agree or agree as responses. 
Table 4

Analysis of instructor responses to usefulness survey of CuVIS

\begin{tabular}{|c|c|c|}
\hline No. & Question & Agree \% (no.) \\
\hline 1 & I was able to use the CuVIS tool for my objective with the visualization. & $91.88(1120)$ \\
\hline 2 & Using the CuVIS tool will improve the quality of my teaching with visualization. & $91.30(1113)$ \\
\hline 3 & $\begin{array}{l}\text { Using the CuVIS tool will give me greater control over my teaching with } \\
\text { visualization. }\end{array}$ & $84.90(1035)$ \\
\hline 4 & $\begin{array}{l}\text { CuVIS tool will enable me to accomplish learning design creation with } \\
\text { visualization more quickly. }\end{array}$ & $79.74(972)$ \\
\hline 5 & $\begin{array}{l}\text { CuVIS tool supports critical aspects of creating a learning design with } \\
\text { visualization. }\end{array}$ & $80.63(983)$ \\
\hline 6 & Using the CuVIS tool for visualization will increase my productivity. & $84.17(1026)$ \\
\hline 7 & Using the CuVIS tool for visualization will improve my job performance. & $81.3(991)$ \\
\hline 8 & $\begin{array}{l}\text { The CuVIS tool for visualization will allow me to accomplish more work than } \\
\text { would otherwise be possible. }\end{array}$ & $73.50(896)$ \\
\hline 9 & Using the CuVIS tool will enhance my teaching effectiveness. & $89.75(1094)$ \\
\hline 10 & $\begin{array}{l}\text { The CuVIS tool will make it easier for me to plan integration of visualization in } \\
\text { my teaching. }\end{array}$ & $86.38(1053)$ \\
\hline 11 & Overall, I find the CuVIS tool to be a useful resource for my teaching. & $89.90(1096)$ \\
\hline
\end{tabular}

\section{Impact on instructors' pedagogical practice}

The research question answered was: What is the impact of the CuVIS tool on the student-centredness of instructors' pedagogic practice? (RQ2). This was measured, through a qualitative study, along three axes: instructors' TPACK for designing student-centred LDs for teaching using visualizations, time allocation for student-centred activities with visualizations and change in sequence of activities.

\section{Participant characteristics}

Participating in the research study was a voluntary activity for the instructors. A subset of 70 instructors who had attended our online pedagogy workshop were approached for the study. These instructors were shortlisted based on the quality (medium to good) of their workshop assignments. They were thus aware of the pedagogical principles but were novices in creating LDs for their classrooms. Out of the 70 contacted, 16 instructors volunteered to participate. Finally, six instructors from the Electrical Engineering and Computer Science domains completed the study. Their age ranged from 35 to 45 years, with average teaching experience of 12 years. They had taught undergraduate level courses with visualizations in medium-sized instructor-mediated classrooms of 70-100 students.

\section{Procedure}

In the learning by design approach we followed (Kali \& Ronen-Fuhrmann, 2011), instructors learn through designing artefacts for teaching their students. Therefore, we tracked the evolution in pedagogic practice of the six instructors creating LDs individually across different time points. At the first time point, they developed an LD for their chosen topic, objective and visualization, without using CuVIS (pre-CuVIS). They were told to make the LDs constructively aligned and in support of meaningful learning with ICT, but no additional scaffolds were provided. At the second time point, they used CuVIS tool to generate an LD for the same topic, visualization and objective as the first time point (CuVIS). They were asked to compare the two LDs on the same topic on the basis of a set of guiding questions and reflect on what they learnt across these two time points. At the third time point, the instructors generated another LD without using CuVIS. They selected a different learning scenario, that is, a different topic and visualization, but the objective type remained the same (postCuVIS). 
Data analysis and results

The LDs created by each of the six instructors across the three time points $(6 \times 3=18)$ were analyzed to track the change in their pedagogical practice. Details of the data analysis have been presented in Banerjee and Murthy (2015). The results below are an extension of the previous results.

(1) TPACK for designing student-centred LDs was measured using a rubric (Koh, 2013) that evaluates the extent of meaningful learning incorporated in LD, on a scale of $0-4$. We adapted it to our context and added the dimension of constructive alignment. The inter-rater reliability of the modified rubric was tested, with Cohen's $\kappa=0.81$. Analysis of the LDs revealed that the average TPACK score for each dimension increased from pre-CuVIS to CuVIS intervention, with instructors being able to sustain that increase even after withdrawal of CuVIS (post-CuVIS); it also increased for a different learning scenario where topic and the visualization chosen were different from pre-CuVIS and CuVIS intervention rounds (Figure 9).

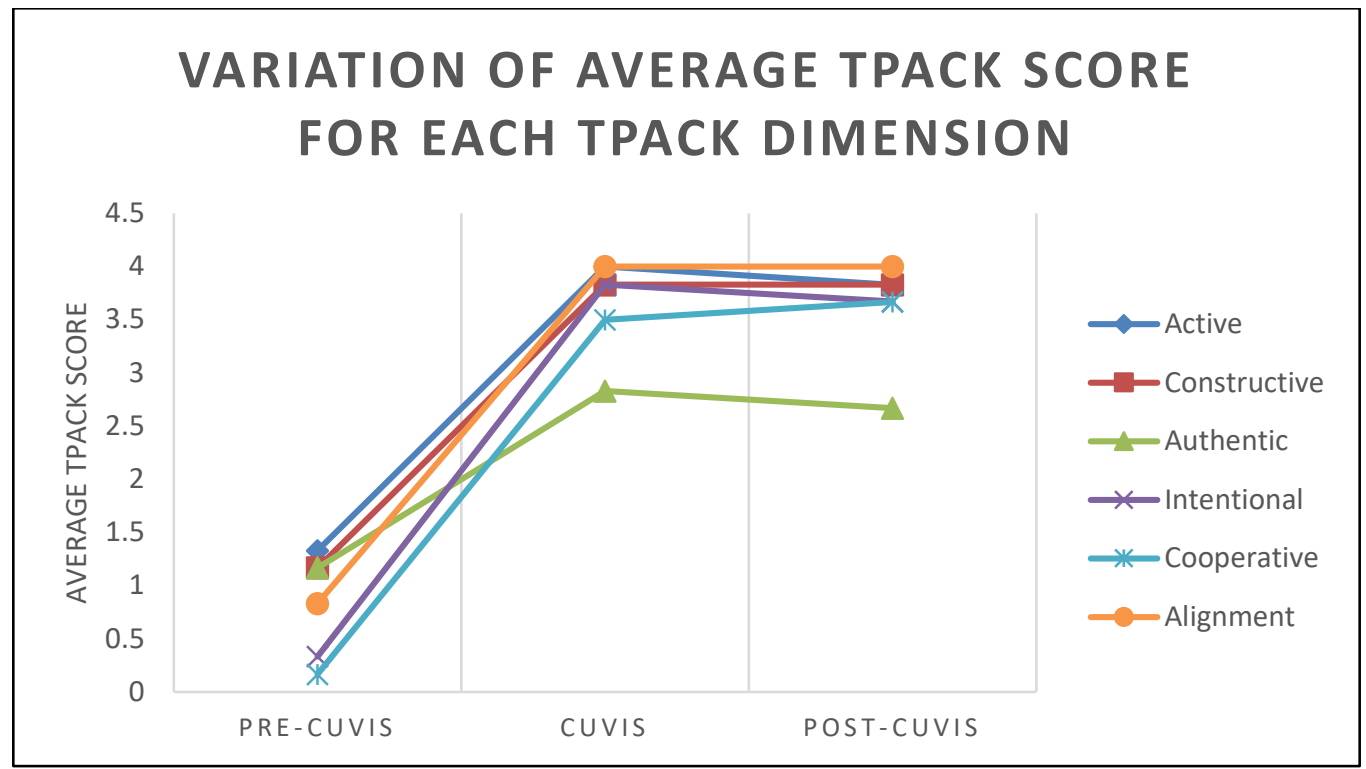

Figure 9. Variation in instructors’ TPACK along each dimension

(2) Time allocation analysis for different type of activities in the LD was evaluated using the method outlined by Kong (2011). Content analysis of each of the 18 LDs led to the identification of three categories of teaching-learning activities designed: category 1 - lecturing without student interaction (with or without visualization), category 2 - guided interactive activity with visualization (individual activity, group activity, feedback through visualization) and category 3 - guided interactive activity but without visualization. The content validity of the categories was established through discussion with another researcher before the final set of categories emerged. The percentage of lesson time allocated for each category gives a measure of the extent of student engagement and student-instructor dialogue planned in the LD. We found category 2 showed the maximum increase in time allocation while Category 3, comprising of activities like class-wide discussion not involving the visualization. Category 1 showed a reduction in time allocation from pre-CuVIS to post-CuVIS phase. This was desirable as it involved lecturing using visualizations. Further analysis within category 2 showed the highest increase occurred for the group activity with visualization (mean increase of 32.06\% across instructors) (Figure 10). 


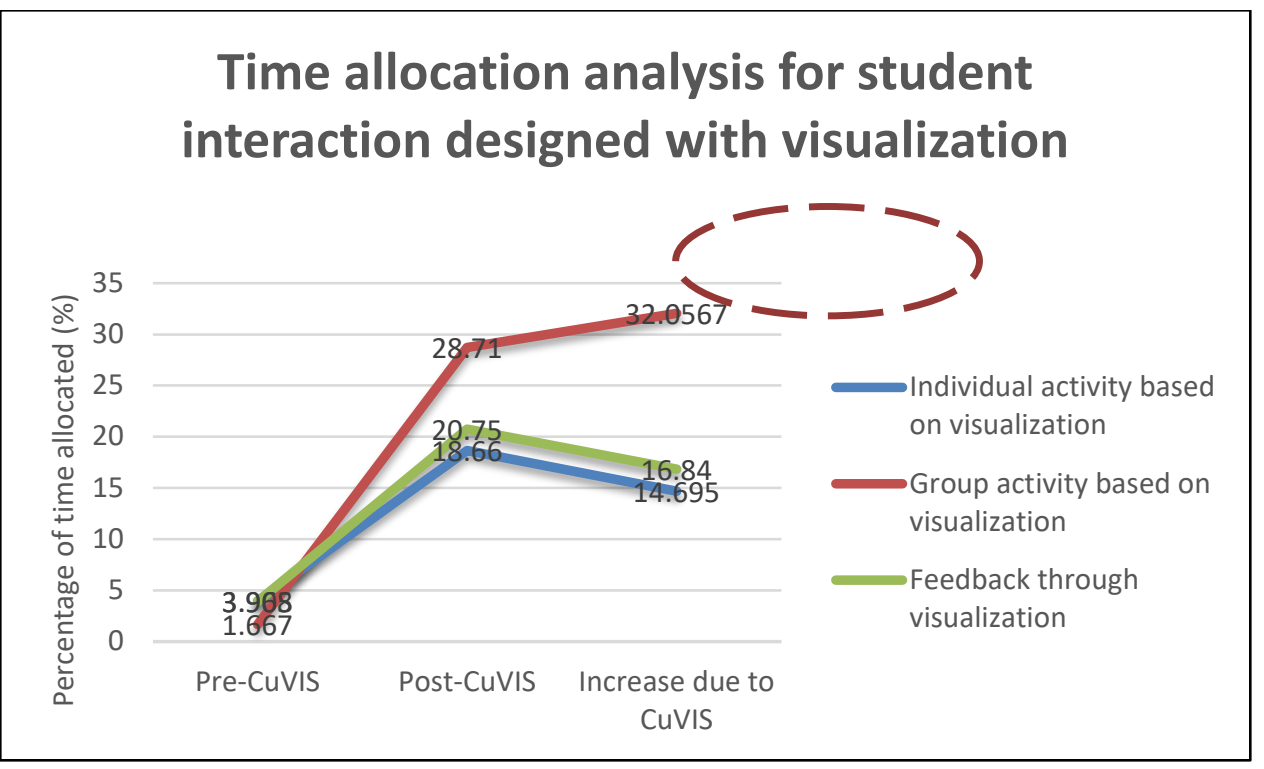

Figure 10. Variation in time allocated within activity with visualization

(3) The temporal sequence of activities analysis, outlined by Laurillard and Ljubojevic (2011), clearly depicts how the sequence of activities changed and a new type of activity was incorporated. In fact, pre-CuVIS to post-CuVIS, instructors migrated from lecturing with visualization to doing a series of interactive activities with visualization (Figure 11).

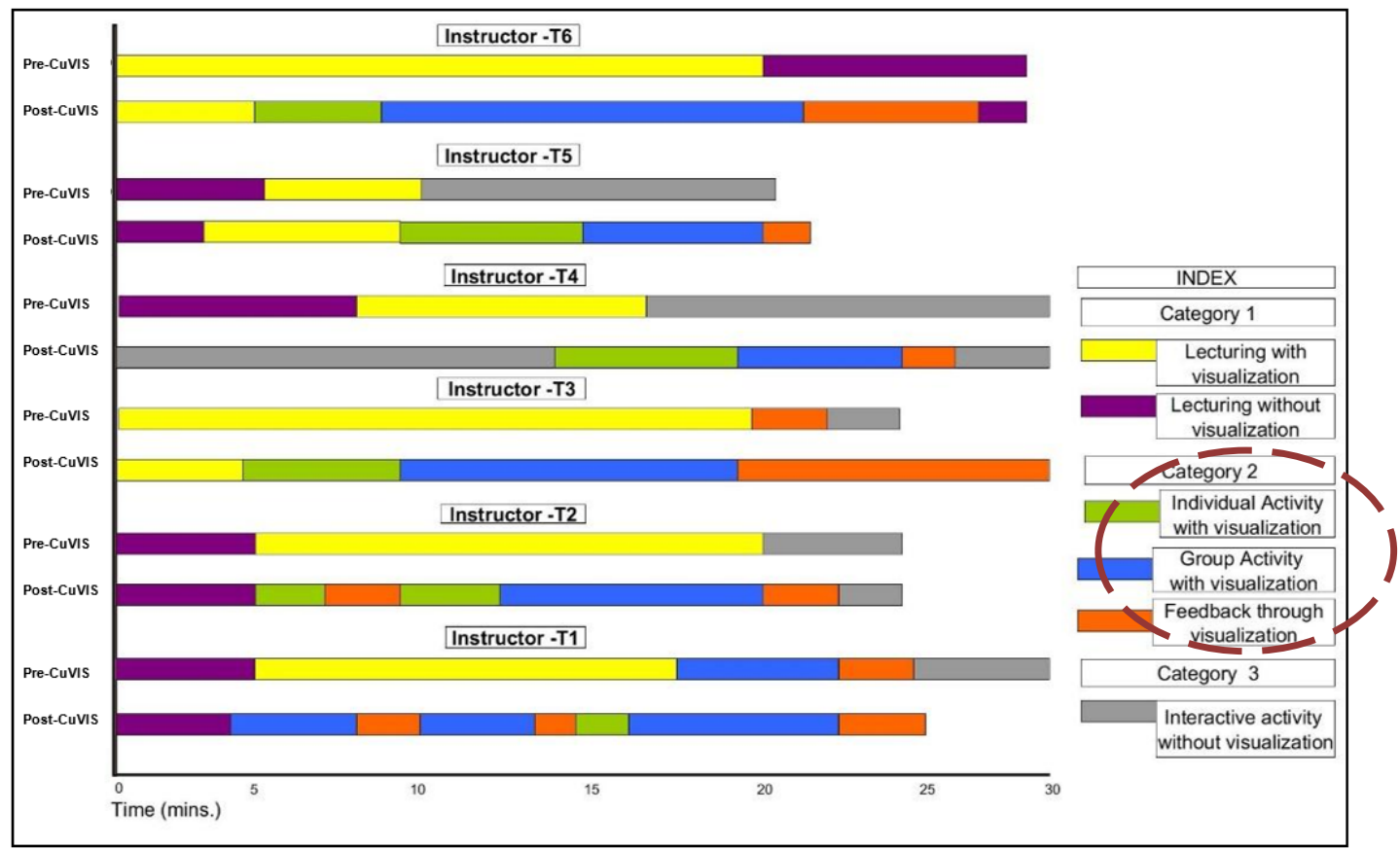

Figure 11: Variation in sequence of activities for each instructor

Thus, results along the three metrics showed that CuVIS intervention led to instructors moving from an instructor-centric LD to a student-centric LD with visualization. 


\section{Impact on student learning}

The research question answered was: What is the impact of CuVIS-generated LDs on student learning with visualization? (RQ3). The impact was measured through two post-test only control-group field experiments with students $(N=375)$, one each in Electrical Engineering (Topic - Signal Transformation) and Computer Science and Engineering (Topic - Pointers). Students in both experiments were undergraduates who were taught with visualization in instructor-mediated classrooms. A quasi-experimental research design was followed in each case. The experimental group was taught with LDs generated using CuVIS for their chosen topic, visualization and learning objective, while the control group was taught with the LD traditionally used by the instructor. Details of both experiments can be found in Banerjee, Murthy, and Iyer (2015) and Banerjee, Patwardhan, and Murthy (2014).

In this paper, we present the student learning data summarized across two experiments (Table 5). The post-test scores of each group in both experiments were normalized to 100 to obtain the total mean score per group. The learning from the LD implementation was measured along two metrics - average post-test scores of the groups and average rate of problem-solving for the group. The rate of problem-solving was calculated as the number of correct responses given to problem-solving questions in unit time. Non-parametric Mann-Whitney $U$ test was performed to compare the post-test results (Table 5). Data analysis results showed that the experimental group taught with CuVIS-generated LDs had a statistically significant average post-test score except in Computer Science and Engineering. The reason for this is probably because the control here was attuned to active learning, unlike in Electrical Engineering. However, the experimental group in both showed a statistically significantly higher rate of problem-solving than the control group. The effect size for post-test score was low, while the effect size for the rate of problem-solving was high in both experiments.

Table 5

Mann-Whitney U test results for student learning in control-group experiments with CuVIS LDs

\begin{tabular}{|c|c|c|c|c|c|c|c|c|}
\hline & \multicolumn{2}{|c|}{ Post-test } & \multirow{2}{*}{$\begin{array}{l}\text { Is difference } \\
\text { significant? }\end{array}$} & \multirow{2}{*}{$\begin{array}{l}\text { Effect } \\
\text { size } \\
\text { (Cohen's } \\
\text { d) }\end{array}$} & \multicolumn{2}{|c|}{ Rate of problem-solving } & \multirow{2}{*}{$\begin{array}{l}\text { Is difference } \\
\text { significant? }\end{array}$} & \multirow{2}{*}{$\begin{array}{l}\text { Effect size } \\
\text { (Cohen's } \\
\text { d) }\end{array}$} \\
\hline & $\begin{array}{l}\text { Experimental } \\
\text { group mean } \\
\text { (SD) }\end{array}$ & $\begin{array}{l}\text { Control } \\
\text { group } \\
\text { mean } \\
(\mathrm{SD}) \\
\end{array}$ & & & $\begin{array}{l}\text { Experimental } \\
\text { group mean } \\
\text { (SD) }\end{array}$ & $\begin{array}{l}\text { Control } \\
\text { group } \\
\text { mean } \\
(\mathrm{SD}) \\
\end{array}$ & & \\
\hline Total & $\begin{array}{l}66.41 \\
(24.53) \\
N=206 \\
\end{array}$ & $\begin{array}{l}66.196 \\
(25.49) \\
N=169 \\
\end{array}$ & $\begin{array}{l}\mathrm{U}=1.49 \mathrm{E} 4 \\
(p=0.017)\end{array}$ & 0.008 & $0.62(0.35)$ & $\begin{array}{l}0.32 \\
(0.15)\end{array}$ & $\begin{array}{l}\mathrm{U}=7.92 \mathrm{E} 3 \\
(p=0.00)\end{array}$ & 1.11 \\
\hline $\mathrm{EE}$ & $\begin{array}{l}85.47 \\
(19.72) \\
N=70\end{array}$ & $\begin{array}{l}68.75 \\
(30.54) \\
N=74\end{array}$ & $\begin{array}{l}\mathrm{U}=1.78 \mathrm{E} 3 \\
(p=0.01)\end{array}$ & 0.65 & $0.29(0.08)$ & $\begin{array}{l}0.21 \\
(0.08)\end{array}$ & $\begin{array}{l}\mathrm{U}=684(p= \\
0.00)\end{array}$ & 0.999 \\
\hline CS & $\begin{array}{l}60.86 \\
(23.61) \\
N=136 \\
\end{array}$ & $\begin{array}{l}60.69 \\
(22.44) \\
N=95 \\
\end{array}$ & $\begin{array}{l}\mathrm{U}=6435 \\
(p=0.96)\end{array}$ & 0.007 & $0.62(0.26)$ & $\begin{array}{l}0.32 \\
(0.13)\end{array}$ & $\begin{array}{l}966.5 \\
(p=0.00)\end{array}$ & 1.45 \\
\hline
\end{tabular}

Notes. EE = Electrical Engineering; CS = Computer Science and Engineering.

\section{Conclusion and discussion}

The broad problem targeted in this paper is that instructors are not able to create student-centred LDs for teaching with ICT. We addressed this problem in the context of science and engineering instructors who teach with visualizations in instructor-mediated classrooms but are novice designers. Thus, our research objective was to develop a tool that will facilitate the transition of instructors from instructor-centric to student-centric LDs with visualizations. In response, we built CuVIS. Figure 12 presents a summary of studies conducted to build CuVIS using DDR methodology. The target users of the tool were involved in every phase of tool development. 


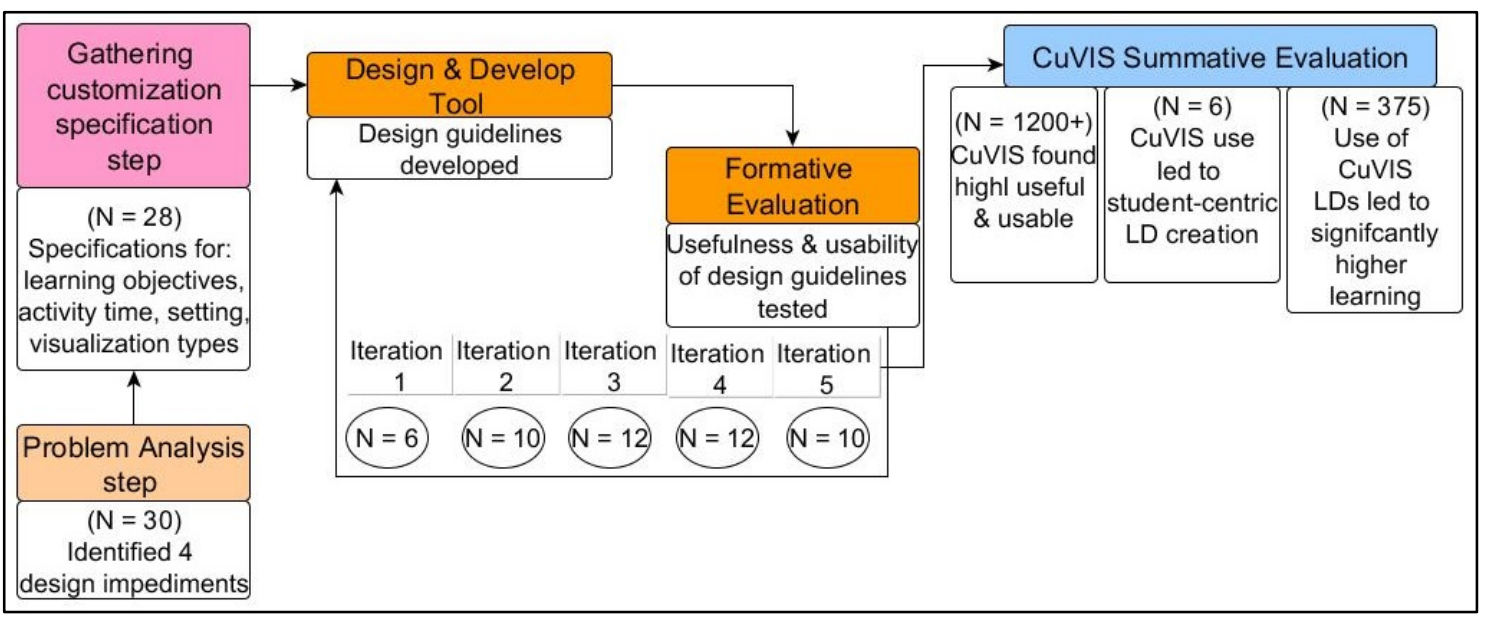

Figure 12. Overview of studies conducted in building CuVIS tool in different steps of DDR

We have conducted evaluations of CuVIS along multiple time points and from many perspectives. Multiple formative evaluation rounds helped us refine the tool and make it more useful and usable to the instructors. This led to positive results in the final large-scale usability and usefulness evaluation using TAM and SUS instruments respectively. Summative evaluation also included a study to examine instructors' ability to design student-centric LDs. Analysis of the study results showed use of CuVIS helped instructors migrate from instructor-centric to student-centric LDs with visualization. Instructor LDs showed increase in time allotted for guided interactive activity with visualization. This was reflected in the increased scores for each instructor along each TPACK dimension. What was notable was that the instructors were able to sustain this improvement even after CuVIS support was removed. This was possibly due to the fact that CuVIS guidelines targeted the specific design impediments that came from their field problems. LD literature reports on design impediments faced by instructors at a broad level, such as problems in translating theory into practice (Laurillard, 2012). But CuVIS guidelines went one level deeper and found specific points where instructor need help, for example, in incorporating all the dimensions of meaningful learning with ICT given their context. Thus, instructors needed guidelines on how to operationalize each dimension in their design practice. The results of summative evaluation studies establish that CuVIS successfully achieves our research objective. Further, the evaluation study was extended to examine the impact on students who are taught using these LDs. This strengthens the evidence of effectiveness of CuVIS and shows that instructors were able to apply CuVIS design guidelines to create LDs that led to effective learning with visualizations.

CuVIS was designed for instructor-mediated classroom settings. To examine its generalizability, we explored using CuVIS with two instructors in a massive open online course in the Electrical Engineering domain. We found they were able to apply the conceptual level guidelines to create constructively aligned and meaningful LDs with visualizations for the topics of Convolution and Fourier transformation. However, the LD blueprints could not be used, thus pointing to the fact that conceptual level guidelines are likely to generalizable to other settings, but not implementation level guidelines without attention to the specific setting. The illustrative examples for CuVIS guidelines are currently limited to Electrical Engineering and Computer Science domains. During multi-domain testing of CuVIS for usefulness and usability, instructors from other domains reported that they were able to create LDs using the guidelines, but had to invest sufficient time to translate the guidelines to their domains. Additional illustrative examples thus need to be added.

There are certain limitations to the CuVIS tool. Firstly, CuVIS offers a given set of objectives to choose from, and similarly suggests a strategy from a given set of strategies. While this was a deliberate decision in order to scaffold novice designers, the approach can be considered as too prescriptive, and may limit instructors' creative ability while creating LDs. Future work could include more open-ended guidance. Secondly, the learning objectives list in CuVIS is not comprehensive. It represents those that instructors in our context typically have while teaching with visualizations. However, design level objectives are not addressed. Research is needed to 
create guidelines both at the conceptual and implementation levels. Thirdly, CuVIS includes a representative set of three active learning strategies (peer instruction, think-pair-share, and predict-observe-explain). The set could be expanded in a future version of CuVIS. Fourthly, the CuVIS LDs do not conform to IMS LD specifications since our focus was pedagogy of teaching with visualization in instructor-mediated classes. Finally, the qualitative study to evaluate the impact on instructors' pedagogic practice involved six instructors. Further, instructors who tested CuVIS through our studies had prior awareness of the benefits of active learning and constructivist pedagogy through a workshop. It is therefore difficult to predict the effectiveness of CuVIS for instructors who have not attended such a workshop. Thus, the number of instructors and type of instructors need to be increased to strengthen the current effectiveness results.

The major contributions of this paper are:

(1) The CuVIS tool, which has been evaluated to enable instructors to create constructively aligned, meaningful LDs while teaching with visualizations in instructor-mediated classrooms

(2) CuVIS design guidelines, both at conceptual and implementation levels, which instructors have found to be useful and usable

(3) The four design impediments identified for designing effective LDs using visualization in instructormediated classrooms: operationalizing constructive alignment, framing group activity questions based on visualization, operationalizing meaningful learning with ICT and design implementation of active learning strategies. These impediments contribute to LD research where identification of design impediments is still an open question (Bennett et al., 2015).

Future work on the CuVIS tool would entail addressing its current limitations and creating a collaborative technology-enabled learning environment where instructors can collaboratively work on their LD projects.

\section{References}

Angeli, C., \& Valanides, N. (2009). Epistemological and methodological issues for the conceptualization, development, and assessment of ICT-TPCK: Advances in technological pedagogical content knowledge (TPCK). Computers \& Education, 52(1), 154-168. https://doi.org/10.1016/j.compedu.2008.07.006

Anderson, L. W., Krathwohl, D. R., Airasian, P., Cruikshank, K., Mayer, R., Pintrich, P., ... Wittrock, M. (2001). A taxonomy for learning, teaching and assessing: A revision of Bloom's taxonomy. New York, NY: Longman.

Banerjee, G., Murthy, S., \& Iyer, S. (2015). Effect of active learning using program visualization in technology-constrained college classrooms. Research and Practice in Technology Enhanced Learning, 10(1), 1-25. https://doi.org/10.1186/s41039-015-0014-0

Banerjee G., \& Murthy S. (2015). CuVIS tool to develop instructors’ competency in creating meaningful learning designs. In H. Ogata, W. Chen, S. C. Kong, \& F. Qiu (Eds.), Proceedings of the 23rd International Conference on Computers in Education (pp. 622-631). Jhongli City: Asia-Pacific Society for Computers in Education. Retrieved from http://www.apsce.net/uploaded/filemanager/8403f3c2-c0c54432-8e4d-f14f70b581f4.pdf

Banerjee, G., Patwardhan, M., \& Murthy, S. (2014). Learning design framework for constructive strategic alignment with visualizations. In C.-C. Liu, H. Ogata, S. C. Kong, \& A. Kashihara (Eds.), Proceedings of the 22nd International Conference on Computers in Education (pp. 963-968). Jhongli City: Asia-Pacific Society for Computers in Education. Retrieved from http://icce2014.jaist.ac.jp/icce2014/wpcontent/uploads/2015/08/ICCE2014-Main-Proceedings-lite.pdf

Bennett, S., Agostinho, S., \& Lockyer, L. (2015). Technology tools to support learning design: Implications derived from an investigation of university instructors' design practices. Computers \& Education, 81, 211-220. https://doi.org/10.1016/j.compedu.2014.10.016

Biggs, J. (1996). Enhancing teaching through constructive alignment. Higher Education, 32(3), 347-364. https://doi.org/10.1007/BF00138871

Brooke, J. (1996). SUS: A quick and dirty usability scale. Usability Evaluation in Industry, 189(194), 4-7. Retrieved from http://www.usabilitynet.org/trump/documents/Suschapt.doc 
Conole, G. (2014). The 7Cs of learning design: A new approach to rethinking design practice. In S. Bayne, C. Jones, M. de Laat, T. Ryberg, \& C. Sinclair (Eds.), Proceedings of the 9th International Conference on Networked Learning (pp. 502-509). Lancaster: University of Lancaster. Retrieved from http://www.lancaster.ac.uk/fss/organisations/netlc/past/nlc2014/abstracts/pdf/conole.pdf

Conole, G., \& Alevizou, P. (2010). A literature review of the use of Web 2.0 tools in higher education: A report commissioned by the Higher Education Academy. Milton Keynes: Higher Education Academy. Retrieved from https://www.heacademy.ac.uk/system/files/conole_alevizou_2010.pdf

Coppola, B. P., \& Krajcik, J. S. (2014). Discipline-centered post-secondary science education research: Distinctive targets, challenges and opportunities. Journal of Research in Science Teaching, 51(6), 679693. https://doi.org/10.1002/tea.21165/full

Curlango-Rosas, C., Ponce, G. A., Lopez-Morteo, G, \& Mendiola, M. (2009). Leveraging Google web search technology to find web based learning objects. In Proceedings of Web Congress (pp. 169-176). New York, NY: IEEE. https://oi.org/10.1109/LA-WEB.2009.11

Davis, F. D. (1989). Perceived usefulness, perceived ease of use, and user acceptance of information technology. MIS Quarterly, 13(3), 319-340. https://doi.org/10.2307/249008

Froyd, J. E., Borrego, M., Cutler, S., Henderson, C., \& Prince, M. J. (2013). Estimates of use of researchbased instructional strategies in core electrical or computer engineering courses. IEEE Transactions on Education, 56(4), 393-399. https://doi.org/10.1109/TE.2013.2244602

Howland, J. L., Jonassen, D., \& Marra, R. M. (2012). Meaningful learning with technology (4th ed.). Boston, MA: Allyn \& Bacon.

Kali, Y., \& Ronen-Fuhrmann, T. (2011). Teaching to design educational technologies. International Journal of Learning Technology, 6(1), 4-23. https://doi.org/10.1504/IJLT.2011.040147

Katsamani, M., \& Retalis S. (2011). Making learning designs in layers: The CADMOS Approach. In M. Baptista Nunes \& P, Isaías (Eds.), Proceedings of the IADIS Multi Conference on Computer Science and Information Systems (pp. 305-312). Retrieved from http://www.iadisportal.org/digital-library/makinglearning-designs-in-layers-the-cadmos-approach

Koh, J.H.L. (2013). A rubric for assessing instructors' lesson activities with respect to TPACK for meaningful learning with ICT. Australasian Journal of Educational Technology, 29(6). https://doi.org/10.14742/ajet.228

Kong, S. C. (2011). An evaluation study of the use of a cognitive tool in a one-to-one classroom for promoting classroom-based dialogic interaction. Computers \& Education, 57(3), 1851-1864. https://doi.org/10.1016/j.compedu.2011.04.008

Laakso, M. J., Myller, N., \& Korhonen, A. (2009). Comparing learning performance of students using algorithm visualizations collaboratively on different engagement levels. Journal of Educational Technology \& Society, 12(2), 267-282. Retrieved from http://www.jstor.org/stable/pdf/jeductechsoci.12.2.267.pdf

Lakkala, M., \& Ilomäki, L. (2015). A case study of developing ICT-supported pedagogy through a collegial practice transfer process. Computers \& Education, 90, 1-12. https://doi.org/10.1016/j.compedu.2015.09.001

Laurillard, D. (2012). Teaching as a design science: Building pedagogical patterns for learning and technology. London: Routledge.

Laurillard, D. (2013). Rethinking university teaching: A conversational framework for the effective use of learning technologies. London: Routledge.

Laurillard, D., \& Ljubojevic, D. (2011). Evaluating learning designs through the formal representation of pedagogical patterns. In J.W. Kohls \& C. Kohls (Eds.), Investigations of e-learning patterns: Context Factors, Problems and Solutions (pp. 86-105). Hershey, PA: IGI Global. https://doi.org/10.4018/978-160960-144-7.ch006

Lim, C. P., \& Hang, D. (2003). An activity theory approach to research of ICT integration in Singapore schools. Computers \& Education, 41(1), 49-63. https://doi.org/10.1016/S0360-1315(03)00015-0

Lukasiak, J., Agostinho, S., Bennett, S., Harper, B., Lockyer, L., \& Powley, B. (2005). Learning objects and learning designs: An integrated system for reusable, adaptive and shareable learning content. Research in Learning Technology, 13(2), 151-169. https://doi.org/10.3402/rlt.v13i2.10993 
McKenney, S. (2001). Computer-based support for science education materials developers Africa: Exploring potentials (Doctoral dissertation, University of Twente, Enschede). Retrieved from https://research.utwente.nl/en/publications/computer-based-support-for-science-education-materialsdevelopers

Morris, M. M. (2008). Evaluating university teaching and learning in an outcome-based model: Replanting Bloom (Doctoral dissertation, University of Wollongong). Retrieved from http://ro.uow.edu.au/theses/784/

Richey, R. C., \& Klein, J. D. (2007). Design and development research: Methods, strategies, and issues. Mahwah, NJ: Lawrence Erlbaum Associates. https://doi.org/10.1007/978-1-4614-3185-5_12

Riess, W., \& Mischo, C. (2010). Promoting systems thinking through biology lessons. International Journal of Science Education, 32(6), 705-725. https://doi.org/10.1080/09500690902769946

Rutten, N., van Joolingen, W. R., \& van der Veen, J. T. (2012). The learning effects of computer simulations in science education. Computers \& Education, 58(1), 136-153. https://doi.org/10.1016/j.compedu.2011.07.017

Shaffer, C. A., Akbar, M., Alon, A. J. D., Stewart, M., \& Edwards, S. H. (2011). Getting algorithm visualizations into the classroom. In Proceedings of the 42nd ACM Technical Symposium on Computer Science Education (pp. 129-134). New York, NY: ACM Press. https://doi.org/10.1145/1953163.1953204

Sorva, J., Karavirta, V., \& Malmi, L. (2013). A review of generic program visualization systems for introductory programming education. ACM Transactions on Computing Education (TOCE), 13(4), 1-64. https://doi.org/10.1145/2490822

Tsai, C. C., \& Chai, C. S. (2012). The "third”-order barrier for technology-integration instruction: Implications for instructor education. Australasian Journal of Educational Technology, 28(6), 1057-1060. https://doi.org/10.14742/ajet.810

Villasclaras-Fernández, E. D., Asensio-Pérez, J. I., Hernández-Leo, D., Dimitriadis, Y., de la Fuente-Valentín, L., \& Martínez-Monés, A. (2011). Implementing computer-interpretable CSCL scripts with embedded assessment: A pattern based design approach. In F. Pozzi \& D. Persico (Eds.), Techniques for fostering collaboration in online learning communities: Theoretical and practical perspectives (pp. 261-277). Hershey, PA: IGI Global.

Webb, M., \& Cox, M. (2004). A review of pedagogy related to information and communications technology. Technology, Pedagogy and Education, 13(3), 235-286. https://doi.org/10.1080/14759390400200183

Corresponding author: Gargi Banerjee, gargib@iitb.ac.in

Australasian Journal of Educational Technology @ 2018.

Please cite as: Banerjee, G., \& Murthy, S. (2018). CuVIS: An interactive tool for instructors to create effective customized learning designs with visualizations. Australasian Journal of Educational Technology, 34(2), 95-116. https://doi.org/10.14742/ajet.3773 